\title{
Penggunaan Mark Routing Untuk Melakukan Switching Jalur Akses Berdasarkan Prioritas Paket Data (Studi Kasus: Kantor PUSKUD JABAR)
}

\author{
Yudi Ramdhani ${ }^{1}$, Riski Mardhianto ${ }^{2}$ \\ 1 Universitas Adhirajasa Reswara Sanjaya \\ e-mail: yudi@ars.ac.id \\ ${ }^{2}$ Universitas Adhirajasa Reswara Sanjaya \\ e-mail: riski.mardianto@gmail.com
}

\begin{abstract}
Abstrak
Jaringan komputer adalah hal yang sudah harus ada pada kantor-kantor saat ini, kebutuhan internet sangatlah tinggi untuk menunjang kegiatan maupun pekerjaan agar menjadi jauh lebih efisien. Di kantor yang terdapat banyak karyawan maupun sub bagian pastilah memiliki situasi kerja yang berbeda, meskipun telah ada limitasi pada setiap bagian maupun setiap komputer/device, namum tetap saja masalah kebutuhan bandwidth kadang masih tetap terjadi, entah itu dikarenakan banyaknya pengguna yang menggunakan jaringan tersebut maupun beberapa pengguna yang menggunakan jalur tersebut untuk internet demi menunggu pekerjaan berikutnya tiba. Dengan menggunakan Mark Routing memungkinkan mikrotik untuk memberikan sebuah tanda/mark pada setiap koneksi dan paket data yang lewat untuk nantinya dapat diatur sedemikian rupa saat melalui jaringan router tersebut, dalam penelitian ini dilakukan pemindahan koneksi yang menuju server dan akses website penunjang pekerjaan akan dialihkan menuju jalur akses gateway ISP2. Diterapkan pula data priority guna memprioritaskan jalur akses kepada paket data penting ketika banyak data melewati jalur akses yang sama dan penggunaan failover untuk mengatasi kegalalan koneksi ketika salah satu jalur akses mati. Dari penerapan 3 teknik diatas didapatkan hasil berupa thoughput yang jauh meningkat dan response time berkurang rata-rata sebesar $68,1 \%$ serta pengalihan gateway pada client ketika mengakses website tertentu yang telah ditentukan agar menuju gateway ISP2.
\end{abstract}

Kata kunci: Failover, Jaringan, Mark Routing, Prioritas Data, Switching.

\begin{abstract}
Computer networks are things that must already exist in offices today, the internet is needed to support activities and work to be much more efficient. In an office where there are many employees and sub-sections, there must be different work situations, even though there are limitations on each part and every computer/device, but still the problem of bandwidth needs occurs, whether it's because so many users who use the network or some users who surfing internet to wait for the next job to arrive. Using the Mark Routing allows the proxy to provide a mark on each connection and data packets that pass to be able to arrange in such a way through the router network, In this research, the connection to the server and connection to website that support the work will be is separated and transferred into ISP2 gateway. Data priority is also applied to prioritize access line for important data packages when a lot of data passes through the same line and using failover to overcome connection failure when one of the gateways dies. From implementing 3 techniques that has ben said giving increased throughput and reduced response time by an average of $68.1 \%$, also gateway will be switching when client access some of the website that has been listed to use ISP2 gateway.
\end{abstract}

Keywords: Data Priority, Failover, Mark Routing, Networking, Switching. 


\section{Pendahuluan}

Pada era Revolusi Industri 4.0 Internet telah menjadi sebuah kebutuhan penting untuk menunjang kegiatan seharihari. Sekarang ini jaringan komputer telah mencangkup seluruh aspek pekerjaan mulai dari kegiatan pada bidang Politik, Ekonomi, Sosial, Budaya, Pendidikan, Jasa, dan Lain (Marr, 2018). Tidak mengherankan kalau sekarang disetiap kantor perusahaan telah terpasang koneksi internet untuk menunjang situasi kerja yang sudah banyak dilakukan secara digital. Dengan kebutuhan tersebut untuk menghasilkan situasi kerja yang efektif membutuhkan koneksi internet yang memadai untuk menunjang kegiatan seharihari mereka (Veryrizkia, 2018).

BBC News dalam survei-nya menyatakan kebanyakan kayawan mengakses internet melalui perangkat digital yang tersedia di kantor untuk mengisi waktu demi menunggu pekerjaan selanjutnya karena jenuh atau karena situasi kerja yang jauh lebih bebas sehingga mereka mencoba mencuri-curi waktu untuk melakukan Cyberloafing (Lowe Calverley \& Grieve, 2017). Dengan tersedianya koneksi gratis pada kantor maupun tempat kerja mendorong para karyawan untuk sering melakukan penyalahgunaan akses internet demi memenuhi kebutuhan pribadi mereka (Armanto, 2017). Dengan banyaknya Cyberloafing itulah pengiriman data menjadi terhambat karena banyaknya jumlah user yang mengakses Internet melalui jalur tersebut. Jika demikian maka diperlukan suatu sistem untuk melakukan memanajemen koneksi dan paket data agar paket data yang berhubungan dengan pekerjaan dapat bergerak secara bebas tanpa terkena buffer dikarenakan padatnya jalur akses yang ada (Wijaya, 2016).

Untuk mengatasi permasalahan diatas penulis mencoba menerapkan metode Load Balancing atau pembagian beban kerja dengan menggunakan router MikroTik routerboard dengan metode $P C C$ dengan melakukan Mark-Routing terhadap koneksi / jenis paket data dari website yang diakses dan prioritasi paket data agar paket data pekerjaan akan jauh lebih diprioritaskan. Load Balancing pada dasarnya adalah pembagian beban kerja kepada dua atau lebih resource yang ada, sehingga pekerjaan akan lebih cepat untuk ditanggani (Segall \& Cook, 2018). Metode $P C C$ sendiri merupakan metode yang sering dipakai dalam Load Balancing yang mana memisahkan jalur akses berdasarkan kriteria-kriteria yang telah ditentukan (Adani, Jusak, \& Pratikno, 2016). Dengan digunakannya 2 buah jalur ISP maka diperlukan juga metode Failover guna mengatasi masalah jika salah satu gateway / ISP mengalami kegagalan koneksi (Pambudi \& Muslim, 2017). Objek penelitian dilakukan pada Kantor Pusat KUD Jawa Barat dikarenakan situasi kerja yang santai membuat banyaknya waktu luang untuk diantara sela-sela pekerjaan membuat karyawan terkadang melakukan akses internet untuk membunuh rasa bosan ketika pekerjaan tidak ada. Dengan banyaknya akses internet koneksi yang digunakan untuk pekerjaan menjadi terhambat dikarenakan padatnya jalur akses.

\section{Metode Penelitian}

Metode yang digunakan adalah metode pengembangan sistem, yang terdiri dari analisa kebutuhan, desain jaringan, tahap konfigurasi, pengujian dan penerapan. Tahap pertama adalah tahap analisa kebutuhan perangkat lunak dan perangkat keras. Perangkat keras yang digunakan untuk implementasi sistem jaringan Load Balancing pada penelitian ini, yaitu Mikrotik RouterOS V6.44 RAM minimal 64MB dan memiliki 5 LAN Port, 2 Buah PC Client dengan Port LAN, dan sebuah Switch dengan kecepatan $100 \mathrm{Mbps}$. Sedangkan untuk perangkat Lunak yang dibutuhkan yaitu Winbox untuk melakukan konfigurasi Mikrotik RouterOS, Packet Capture untuk menangkap dan membaca paket data yang melalui jaringan, dan Network Troubleshooter, untuk melakukan pingging dan traceroute dalam mengetes aturan sistem jaringan yang berjalan.

Tahap kedua yaitu desain jaringan. Desain jaringan meliputi pembuatan topologi jaringan yang sesuai dengan kebutuhan, dan dapat menghasilkan kinerja yang baik. Tahap ketiga adalah tahap konfigurasi. Melakukan konfigurasi router Mikrotik dengan menggunakan aplikasi winbox, terdapat beberapa konfigurasi yang akan dilakukan yaitu konfigurasi dasar, konfigurasi mark routing, konfigurasi data priority dan konfigurasi failover. 


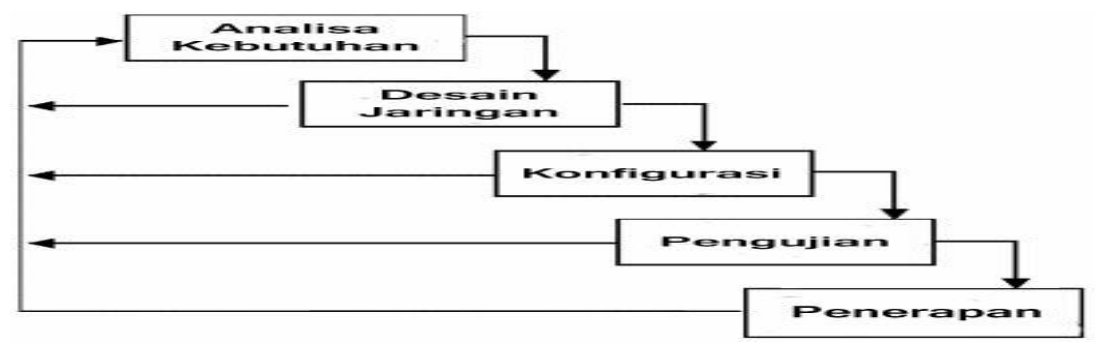

Gambar.1 Metode Pengembangan Sistem

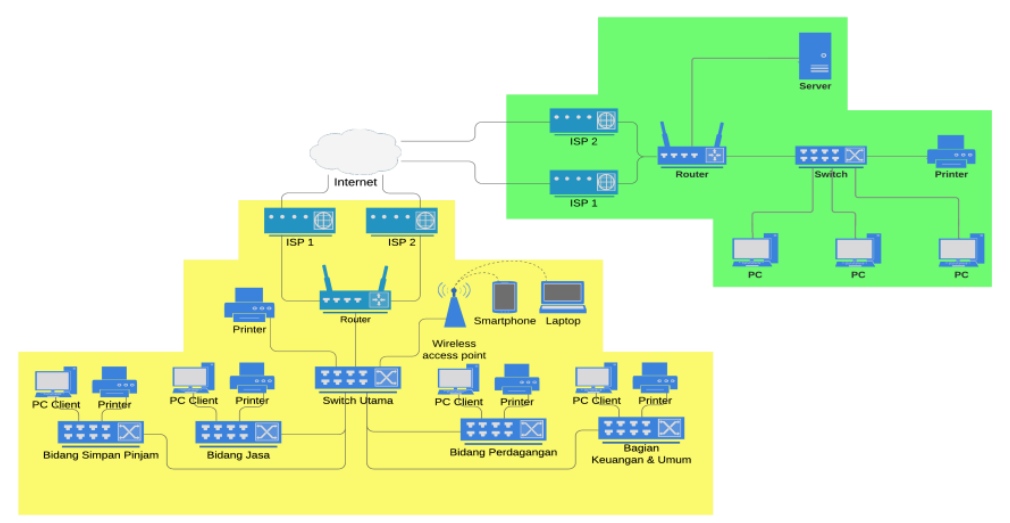

\section{Gambar.2 Topologi jaringan LAN dengan 2 ISP dan 1 Jaringan Lokal}

Tahap keempat adalah pengujian. Pengujian dilakukan terhadap teknik mark routing, data priority dan failover agar dapat bekerja sebagaimana mestinya. Tahap kelima yaitu penerapan. Pada tahapan ini, teknik mark routing, data priority dan failover diterapkan dan dilakukan analisa sehingga dapat diketahui apakah hasil yang ditunjukkan sesuai dengan yang direncanakan.

\section{Hasil dan Pembahasan}

Pada tahap ini akan dibahas tentang hasil penerapan teknik $P C C$ alias mark routing dan failover, meliputi desain jaringan, konfigurasi, pengujian dan analisis. Desain jaringan digunakan untuk memilih dan merancang topologi jaringan yang sesuai. Untuk menerapkan mark routing dan failover, dibutuhkan lebih dari satu IP publik. Dalam penelitian ini dibuat 7 buah koneksi yang terdiri dari dua jalur publik/internet dan satu jalur lokal sebagai akses pengguna dalam pengujian, seperti yang ditunjukkan pada Gambar 2. Simulasi dilakukan pada Software GNS3 dengan melakukan serangkaian tes yang ada sebelum nantinya diterapkan pada jaringan sesungguhnya ketika hasil telah sesuai dengan yang diharapkan.

3.1. Konsep dan Penerapan Simulasi

A. Konsep sebelum Load Balancing
Dengan hanya menggunakan 1 buah ISP saja menghasilkan beban kerja yang sangat berat ketika jam sibuk terjadi. Berdasarkan hasil analisa dan observasi, terdapat beberapa permasalahan yang terjadi, yaitu:

1)Koneksi sering terjadi failure dikarenakan jalur akses yang padat.

2)Paket data yang menunjang kegiatan kerja terhambat dikarenakan padatnya akses internet.

3)Ketika terjadi gangguan terhadap ISP yang digunakan, koneksi internet terputus secara total dan merskipun ada akan terasa sangat lambat dari ketika jalur akses saat padat.

B. Konsep penerapan Load Balancing

Penerapan Metode Load Balancing adalah untuk menunjang kegiatan kerja Kantor Pusat KUD Jawa Barat yang diharapkan dapat mengatasi permasalahan-permasalahan yang telah terjadi sebelumnya. Perubahan paling mencolok pada penerapan ini adalah penambahan 1 buah ISP baru guna membagi beban kerja yang ada.

Konfigurasi dasar pada mikrotik dapat menggunakan software khusus yang digunakan yaitu Winbox maupun melalui CLI dengan putty atau mikrotik interface. Konfigurasi dasar meliputi konfigurasi 
Interfaces List, IP Address, Domain Name System (DNS), dan NAT.

1) Interface List

Pengelompokan interface dilakukan untuk mempermudah konfigurasi mark routing nantinya, konfigurasi dilakukan melalui perintah script berikut:

/interface 7ist

add name=Internet

/interface list member

add interface $=$ ISP 1

1ist=Internet

add interface $=$ ISP2

1 ist=Internet

2) Pemberian IP Address

IP Address diberikan kepada setiap interfaces yang akan digunakan dan telah dikelompokkan sebelumnya, konfigurasi dilakukan melalui perintah script berikut:

/ip dhcp-client

add interface $=$ ISP 1

add interface $=$ ISP2

/ip address

add address=192.168.1.1/24

interface $=$ Loca]

network $=192.168 .1 .0$

3) Pemberian DNS

DNS (Domain Name System) adalah sistem yang bertugas untuk menerjemahkan nama komputer menjadi IP Address, konfigurasi dilakukan melalui perintah script berikut:

/ip dns

set a110w-remote-request $=y e s$ server $=8.8 .8 .8,8.8 .4 .4$

4) NAT

Agar komputer client dapat terkoneksi dengan internet, maka ip private client haruslah dimasquerade dengan ip publik, konfigurasi dilakukan melalui perintah script berikut:

add action=masquerade

chain=srcnat out-

interface $=$ ISP 1

add action=masquerade

chain=srcnat out -

interface=ISP2

5) Pembuatan Daftar IP Address

Pembuatan daftar ini diperlukan ketelitian dan kesabaran dikarenakan untuk membuatnya diharuskan menganalisa paket data satu persatu dengan software packet capture. Dengan melakukan analisa pada koneksi dan paket data yang dianggap penting / menunjang pekerjaan sehingga didapatkan ip address maupun port tujuan untuk nantinya didaftarkan sebagai alamat yang akan diutamakan menurut prioritasnya.

Penangkapan IP Address maupun port dapat dilakukan menggunakan aplikasi Wireshark pada komputer client, SLL Capture pada handphone berjenis Android, maupun langsung melalui fitur Torch pada MikroTik RouterOS. Untuk list website IIX dapat diperoleh melalui website Mikrotik.co.id dengan memasukkan perintah script sebagai berikut:

/tool fetch

address=ixp . mikrotik . co . id

src-path=/download/nice. rsc mode=http ;

import nice.rsc

6) Gateway

Setelah konfigurasi IP Address dan DNS, maka selanjutnya lakukan konfigurasi pada default route dari masing-masing gateway ISP yang digunakan. Pastikan untuk menambahkan fungsi check-gateway agar fungsi failover dapat berjalan jika salah satu gateway tujuan terputus. Berikut adalah script yang digunakan:

/ip route

add gateway=192 .168 .10 .1

check-gateway $=$ ping distance $=1$ add gateway $=192.168 .20 .1$

check-gateway=ping distance $=2$

7) Queue Tree

Queue Tree digunakan untuk melakukan limitasi bandwidth dan pengimplementasian prioritas paket data yang bergerak dalam jaringan.

Berikut adalah script yang digunakan:

/queue tree

add 7 imit-at $=10 \mathrm{M}$ max-

1 imit=20M name=Down 1oad

parent $=$ globa 7 queue $=$ pcq down 7 oad-default

add 7 imit-at $=3 \mathrm{M}$ max-1imit $=6 \mathrm{M}$

name $=$ Up 1 oad parent $=g 1$ oba 1

queue $=$ pcq- up 1 oad - defau $1 t$

add 1imit-at $=2500 \mathrm{k}$ max-

1 imit $t=5 \mathrm{M}$ name $=$ Tektaya-Down

packet-mark=Tektaya_Down

parent=Download priority $=1$

queue $=$ pcq-down 1 oad - default

add 1 imit-at $=750 \mathrm{k}$ max-

1 imit $=1500 \mathrm{k}$ name=Tektaya-up

packet-mark=Tektaya_up

parent=upload priority $=1$

queue $=p c q-$ upload - default 
Queue Download dan upload merupakan parent utama untuk setiap queue yang akan dibuat dengan total bandwidth yang dimiliki, selanjutnya diatur queue untuk setiap packet data yang akan dilakukan prioritasi, seperti nama paket, lebar bandwith, lebar maksimal alokasi ketika jalur kosong, dan nomor prioritas. Prioritas yang bisa diberikan terdiri dari nomor 1 sampai 8 , dengan nomor 1 paling tinggi dan 8 paling rendah.

8) Mangle

PCC akan diimplementasikan dalam melakukan koneksi berdasarkan alamat asal koneksi dan alamat tujuan koneksi yang terjadi. Pada metode PCC setiap paket data yang sesuai dengan kriteria yang telah diberikan akan diberikan sebuah tanda rute yang nantinya akan diteruskan menuju gateway yang telah diatur berdasarkan tanda yang ada pada setiap koneksi tersebut.

$$
\text { Load Balancing }
$$

yang

diimplementasikan ini hanya menggunakan 2 jalur koneksi internet, yang berarti antriannya akan terbentuk 2,0 dan 2,1. Pada mikrotik koneksi yang telah ditandai akan diimplementasikan dalam bentuk koneksi baru atau disebut dengan newconnection-mark. Dalam praktiknya, penanda untuk koneksi menuju ISP1 dinamai dengan Mark_to_ISP1 dan penanda untuk koneksi menuju ISP2 dinamai dengan Mark_to_ISP2. Berikut adalah script konfigurasinya:

/ip firewa17 mangle

add action=mark-connection

chain=prerouting dst-address-

list=whatsapp in-interface $=$ Loca 1 new-connection-

mark=whatsapp_conn

passthrough=yes per-connection-

classifier=both-addresses: $2 / 0$

src-address=192 $.168 \cdot 1.0 / 24$

add action=mark-routing

chain=prerouting connection-

mark=whatsapp_conn in-

interface=Loca 1 new-routing-

mark=whatsapp_route

passthrough=yes

add action=mark-routing

chain=output new-routing-

mark=whatsapp_route out-

interface $=$ Locā 7 packet -

mark=WA_Packets passthrough=yes

add action=mark-routing

chain=prerouting in- interface $=$ Local new-routingmark=Mark_to_ISP2

passthrough=yes routing-

mark=whatsapp_route dst-address-7ist=whatsapp

merupakan daftar IP Address website whatsapp yang telah dibuat pada tahapan nomor 5 , sehingga koneksi yang menuju list tersebut akan dilakukan pengalihan koneksi menuju jalur gateway ISP2 dikarenakan whatsapp marupakan salah satu website penunjang pekerjaan.

Kemudian dilakukan penandaan setiap paket data berdasarkan koneksi yang telah dibuat sebelumnya agar dapat diatur tingkat prioritasnya. Berikut adalah script yang digunakan:

/ip firewa11 mangle

add action=mark-packet

chain=forward comment=WA_Down

in-interface-1ist=Internet new-

packet-mark=WA_Down out-

interface $=$ Loca 1 passthrough $=$ no

src-address-1ist=whatsapp

add action=mark - packet

chain=forward comment=WA_Up

connection-mark=whatsapp_conn

in-interface=Loca 1 new-packet-

mark=WA_Up out-interface-

1ist=Internet passthrough=no Konfigurasi diatas akan memberikan tanda pada setiap paket data yang berada didalam koneksi whatsapp diatas. Kemudian dilakukan penandaan pada koneksi dan paket data yang tidak terprioritaskan, dengan menggunakan alamat nice.rsc yang sebelumnya telah didapatkan melalui website Mikrotik.co.id. perintah konfigurasi sama seperti perintah whatsapp daitas namun untuk gatewaynya ditunjukan kepada gateway ISP1.

Kemudian dilakukan konfigurasi gateway untuk masing-masing koneksi yang telah dibuat dengan ketentuan untuk Mark_to_ISP1 akan diarahkan ke alamat 192.168.10.1/24. Dan untuk Mark_to_ISP2 akan diarahkan ke alamat 192.168.20.1/24. Berikut adalah script yang digunakan:

/ip route add gateway $=192.168 \cdot 10.1$ routing-mark=Mark_to_ISP1 checkgateway=ping distance $=1$

add gateway $=192.168 \cdot 20.1$

routing-mark=Mark_to_ISP2 checkgateway=ping distance $=1$

\subsection{Pengujian Tracert}

Pengujian ini dilakukan untuk melihat apakah hasil dari mark routing telah berhasil diterapkan. Pengujian dilakukan 
dengan tracert website whatsapp, gmail, situs internasional, situs IIX dan server tektaya.

Dari hasil tracert website yang telah dilakukan mark routing didapatkan bahwa website yang menunjang produktifitas pekerjaan akan diarahkan kepada gateway Modem ISP2. Untuk daftar lengkapnya bisa dilihat pada tabel dibawah ini:

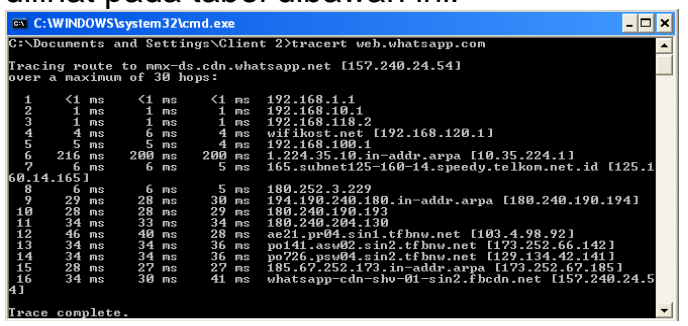

Gambar.3 Hasil Tracert website whatsapp

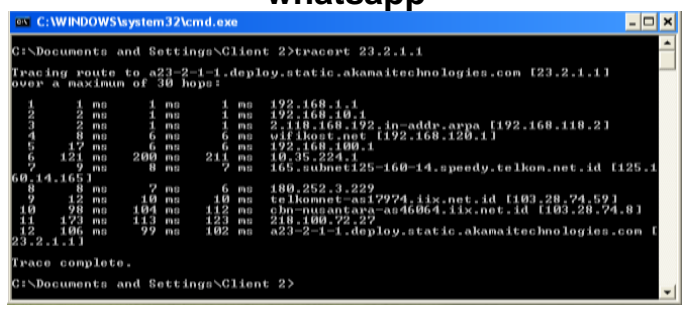

Gambar.4 Hasil Tracert website IIX

Tabel.1 Mark Route

\begin{tabular}{ll}
\hline Tujuan & Gateway \\
\hline Whatsapp & 192.168 .20 .1 \\
\hline Gmail & 192.168 .20 .1 \\
\hline Server Tektaya & 192.168 .20 .1 \\
\hline Facebook & 192.168 .10 .1 \\
\hline Youtube & 192.168 .10 .1 \\
\hline Situs IIX & 192.168 .10 .1 \\
\hline \multicolumn{1}{c}{ Dari tabel 1 dapat disimpulkan }
\end{tabular}

bahwa situs internasional seperti facebook, dan youtube akan melalui jalur akses menuju gateway modem ISP1, begitu pula dengan situs yang terdaftar sebagai IIX melalui list nice.rsc akan ditunjukan menuju gateway modem ISP1. Sedangkan untuk website yang menunjang pekerjaan seperti Whatsapp, GMail meskipun merupakan situs internasional tetapi karena sudah dipisahkan melalui mangle maka akan diarahkan menuju jalur akses gateway modem ISP2 bersamaan dengan koneksi menuju server tektaya.

\subsection{Pengujian Ping}

Pengujian ping ini dilakukan untuk melihat apakah hasil dari mark routing dan prioritasi bandwidth telah berhasil diterapkan. Ping dilakukan dengan melihat waktu response time dari website whatsapp, gmail, facebook, situs IIX dan server tektaya.

Pada gambar 6 adalah hasil tes ping pada website whatsapp, sedangkan pada gambar 5 adalah hasil tes ping pada server tektaya. Kedua tes dilakukan saat akses internet sedang padat. Dengan dilakukannya mark routing membuat kedua alamat tadi dialihkan jalur aksesnya ke gateway ISP2 sehingga meskipun jalur akses sedang padat tidak akan berpengaruh karena sudah melewati jalur akses yang berbeda. Penerapan Bandwith priority juga membantu melakukan optimasi dengan mengutamakan paket data dengan prioritas tinggi untuk diberikan jaur akses yang tersedia ketika banyak data melalui satu jalur akses yang sama.

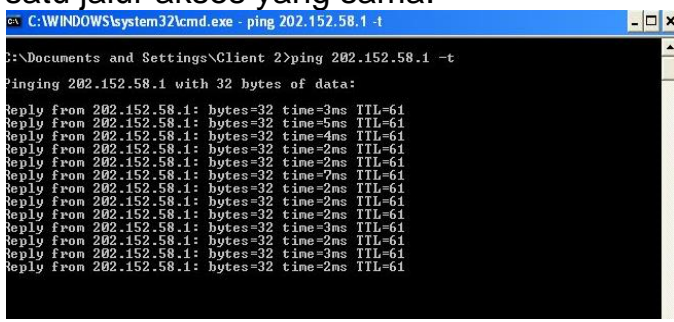

Gambar.5 Hasil ping server tektaya

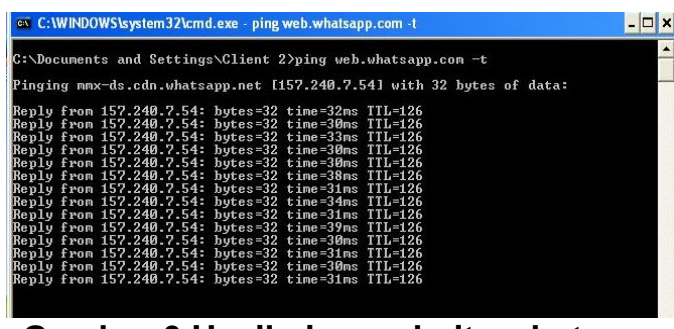

Gambar.6 Hasil ping website whatsapp

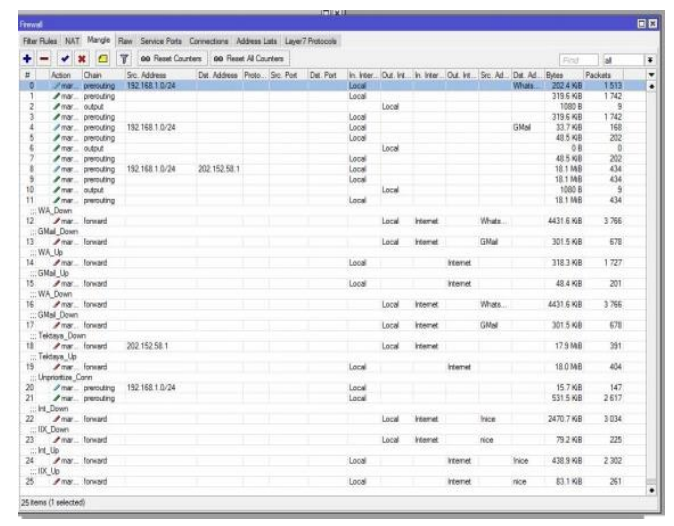

Gambar.7 Bandwidth traffic pada mangle (mark routing) 


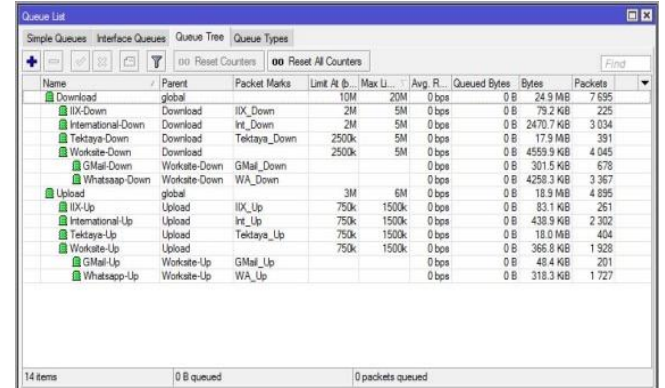

Gambar.8 Bandwidth traffic pada Queue Tree

Pada gambar 7 terdapat mangle yang bentuk untuk melakukan mark routing berdasarkan alamat tujuan dan menamaan paket data berdasarkan tujuannya untuk nantinya akan diatur prioritasnya pada Queue Tree. Hasil dari rata-rata tes ping sebelum penerapan mark routing dengan bandwidth priority dan sesudah penerapan mark routing dengan bandwidth priority bisa dilihat pada tabel dibawah:

Tabel.2 Urutan Prioritas Data

\begin{tabular}{lc}
\hline \multicolumn{1}{c}{ Tujuan } & Prioritas \\
\hline Server Tektaya & 1 \\
\hline Worksite & 2 \\
\hline Situs IIX & 3 \\
\hline Situs International & 4 \\
\hline
\end{tabular}

Tabel.3 Hasil Ping

\begin{tabular}{lcc}
\hline Tujuan & $\begin{array}{c}\text { Sebeum } \\
\text { Mark } \\
\text { Routing }\end{array}$ & $\begin{array}{c}\text { Sesudah } \\
\text { Mark } \\
\text { Routing }\end{array}$ \\
\hline Whatsapp & $126.4 \mathrm{~ms}$ & $34.3 \mathrm{~ms}$ \\
\hline Gmail & $98.1 \mathrm{~ms}$ & $30 \mathrm{~ms}$ \\
\hline Tektaya & $49.6 \mathrm{~ms}$ & $4.6 \mathrm{~ms}$ \\
\hline Situs IIX & $32.5 \mathrm{~ms}$ & $20.7 \mathrm{~ms}$ \\
\hline Facebook & \multicolumn{1}{c}{$121.9 \mathrm{~ms}$} & $35.1 \mathrm{~ms}$ \\
\hline \multicolumn{1}{c}{ Hasil } & pengujian pada tabel 3
\end{tabular}

menunjukkan bahwa, setelah dilakukannya penerapan mark routing dan prioritas data menghasilkan response time yang lebih kecil pada setiap paket data, dikarenakan mikrotik melakukan prioritasi jalur akses yang tersisa kepada paket data yang memiliki prioritas tertinggi pada jalur teersebut. Perubahan signifikan terlihat pada website whatsapp, gmail dan server tektaya yang dilakukan route melalui jalur gateway ISP2, sedangkan pada facebook penurunan response time terjadi dikarenakan jalur akses menuju gateway modem ISP1 menjadi lebih lancar karena paket data pekerjaan telah dialihkan menuju jalur akses gateway modem ISP2.

\subsection{Pengujian Failover}

Secara definisi Failover dapat diartikan sebagai "ketika node yang biasa digunakan mengalami kegagalan, maka terdapat node alternatif yang siap untuk mengambil alih pekerjaan pada jalur tersebut" (Edwards, Bramante, \& Martin, 2006). Pengujian Failover dilakukan dengan cara memutuskan salah satu koneksi internet baik itu pada modem ISP1 maupun pada modem ISP2. Dalam pratiknya dilakukan pemutusan hubungan dari modem ISP2. Ketika koneksi dari modem ISP2 terputus, semua client yang mengakses website yang di mark route ke gateway ISP2 ternyata masih tetap bisa terhubung ke website tersebut. Perpindahan koneksi ini hanya terjadi dalam selang waktu hanya beberapa detik saja, karena itu ketika ada client yang sedang melakukan transfer data akan terdapat sedikit packet loss ketika pemutusan terjadi, ini dikarenakan mikrotik masih menganggap jalur tersebut masih aktif. Ketika terjadi packet loss mikrotik secara otomatis akan melakukan pengecekan terhadap jalur koneksi yang masih aktif dan mengalihkan seluruh koneksi ke jalur internet tersebut, sehingga client tersebut dapat melanjutkan aktifitasnya.

\section{Kesimpulan}

Berdasarkan hasil penelitian yang didapat maka dapat disimpulkan bahwa penggunaan metode $P C C$ alias mark routing dapat memisahkan jalur akses pengguna ke situs yang ditetapkan sebagai prioritas seperti whatsapp, gmail, sever tektaya dengan melalui jalur akses yang berbeda maka tidak akan terganggu oleh jalur koneksi lain meskipun akses internet sedang padat. Ditambah dengan diterapkannya prioritasi bandwith pada setiap paket data yang melewati mikrotik, paket data dengan prioritas tertinggi akan jauh lebih diutamakan dalam pemberian jalur akses yang ada ketika banyak paket yang melalui jalur akses yang sama. Dengan failover memungkinkan mikrotik untuk melakukan pemindahan jalur akses gateway pada setiap koneksi ketika gateway tujuan mengalami kegagalan.

\section{Referensi}

Adani, M. F., Jusak, \& Pratikno, H. (2016). ANALISIS PERBANDINGAN METODE LOAD BALANCE PCC DENGAN NTH MENGGUNAKAN 
MIKROTIK. Journal of Control and Network System, 5(1), 119-125. Retrieved from http://jurnal.stikom.edu/index.php/jcon e/article/view/1110/604

Armanto. (2017). Perancangan Pengelolahan Jaringan Load Balancing Dan Fileover Menggunakan Router Mikrotik Rb 951 Series Pada Stkip Pgri Lubuklinggau. Jusikom, 12(1), 145.

Edwards, J., Bramante, R., \& Martin, A. (2006). Nortel Guide to VPN Routing for Security and VolP (1st ed.). Indianapolis: Wiley Publishing, Inc.

Lowe Calverley, E., \& Grieve, R. (2017). Apakah kantor bisa menghentikan kebiasaan karyawan curi-curi online saat bekerja? Retrieved April 3, 2019, from BBC News website: https://www.bbc.com/indonesia/vertcap-41813370

Marr, B. (2018). What is Industry 4.0? Here's A Super Easy Explanation For Anyone. Retrieved April 3, 2019, from Forbes website: https://www.forbes.com/sites/bernard marr/2018/09/02/what-is-industry-4-0heres-a-super-easy-explanation-foranyone

Pambudi, R., \& Muslim, M. A. (2017). Implementasi Policy Base Routing dan Failover Menggunakan Router Mikrotik untuk Membagi Jalur Akses Internet di FMIPA Unnes. Jurnal Teknologi Dan Sistem Komputer, 5(2), 57.

https://doi.org/10.14710/jtsiskom.5.2.2 017.57-61

Segall, R. S., \& Cook, J. S. (2018). Handbook of Research on Big Data Storage and Visualization Techniques (R. S. Segall \& J. S. Cook, Eds.). Hershey: IGI Global.

Veryrizkia. (2018). Manfaat Teknologi Informasi di Berbagai Bidang. Retrieved April 3, 2019, from web.ugm.ac.id website: http://veryrizkia.web.ugm.ac.id/2018/0 2/12/manfaat-teknologi-informasi-diberbagai-bidang/

Wijaya, A. (2016). Perancangan dan Implementasi Sistem Jaringan Multiple ISP Menggunakan Load Balancing PCC dengan Failover. Skripsi, 1-11. 